Pure Appl. Chem., Vol. 74, No. 1, pp. 11-17, 2002.

(C) 2002 IUPAC

\title{
Functionalized main-group organometallics for organic synthesis*
}

\author{
Paul Knochel ${ }^{\ddagger}$, Eike Hupe, Wolfgang Dohle, David M. Lindsay, \\ Véronique Bonnet, Guy Quéguiner, Andreas Boudier, Felix Kopp, \\ Stéphane Demay, Naka Seidel, M. Isabel Calaza, Viet Anh Vu, \\ Ioannis Sapountzis, and Tanasri Bunlaksananusorn
}

Ludwig-Maximilians-Universität München, Department Chemie, Butenandtstrasse 5-13, Haus F, 81377 München, Germany

Abstract: Highly functionalized Grignard-reagents can be easily obtained by an iodine-magnesim exchange reaction and further reacted with various electrophiles. Via a B-Zn exchange reaction, a formal Michael addition with umpolung of the reactivity can be achieved. Chiral phosphine ligands can be easily synthesized by a 2.3 sigmatropic rearrangement and used successfully in asymmetric synthesis.

\section{INTRODUCTION}

Functionalized organometallic reagents are versatile intermediates for the preparation of complex polyfunctional molecules [1]. In this lecture, the preparation and reactions of new polyfunctional aryl- and alkenylmagnesium reagents will be discussed. Functionalized chiral zinc reagents have been used to perform a novel formal Michael addition reaction with inversion of polarity and finally, new maingroup, metal-catalyzed addition reactions of diorganophosphines $\left(\mathrm{R}_{2} \mathrm{PH}\right)$ and carbonyl derivatives to unactivated alkenes will be reported.

\section{PREPARATION OF FUNCTIONALIZED ORGANOMAGNESIUM REAGENTS}

Functionalized organomagnesium reagents can be readily prepared by performing an iodine-magnesium exchange reaction [2]. This reaction tolerates a broad range of functionalities, and even an electrophilic methyl ester group is tolerated in this exchange reaction. Thus, methyl-4-iodobenzoate is readily converted into the magnesium reagent $\mathbf{1}$, which is stable for several hours at $0{ }^{\circ} \mathrm{C}$. It reacts in good yields with various aldehydes leading to the benzylic alcohols $\mathbf{2}$ and $\mathbf{3}$ (Scheme 1).
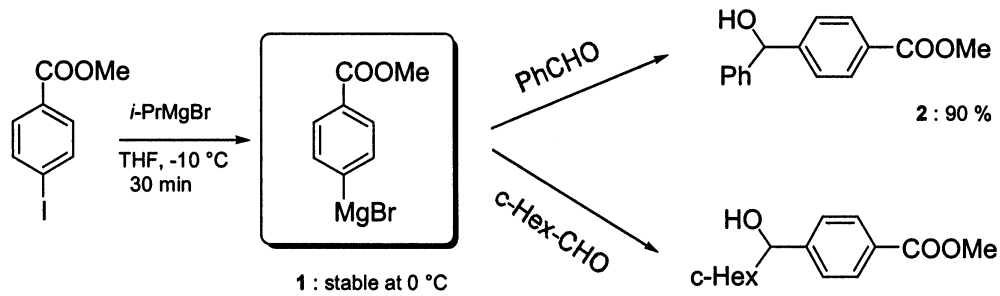

$3: 72 \%$

Scheme 1

*Lecture presented at the $11^{\text {th }}$ IUPAC International Symposium on Organometallic Chemistry Directed Towards Organic Synthesis (OMCOS-11), Taipei, Taiwan, 22-26 July 2001. Other presentations are presented in this issue, pp. 1-186.

${ }^{\ddagger}$ Corresponding author: E-mail: Paul.Knochel@cup.uni-muenchen.de 
Remarkably, various nitrogen functionalities, such as amines or nitro groups, are tolerated in these reactions, and the resulting polyfunctional aminated Grignard reagent can be used for the preparation of highly functionalized indoles like 4 (Scheme 2).

Scheme 2<smiles>CC=Nc1c(I)cc(C(=O)OCC)cc1I</smiles><smiles>C=C(Cc1cc(OCC)cc(I)c1N)OCC(=O)OCC(=O)OCC</smiles>

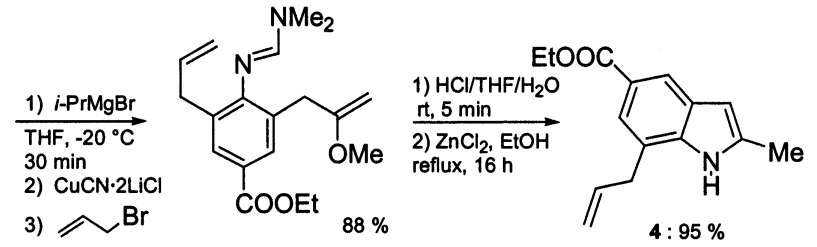

These Mg-organometallics also readily undergo palladium-catalyzed cross-coupling reactions under mild conditions [3] with chloro- or bromo-pyridines like 5. The reaction may involve a palladate intermediate such as $\mathrm{ArPdL}_{2}{ }^{-} \mathrm{MgX}^{+}$, which reacts rapidly with the 2-halopyridine via an addition-elimination mechanism leading to the expected products such as 6 in $95 \%$ (Scheme 3).
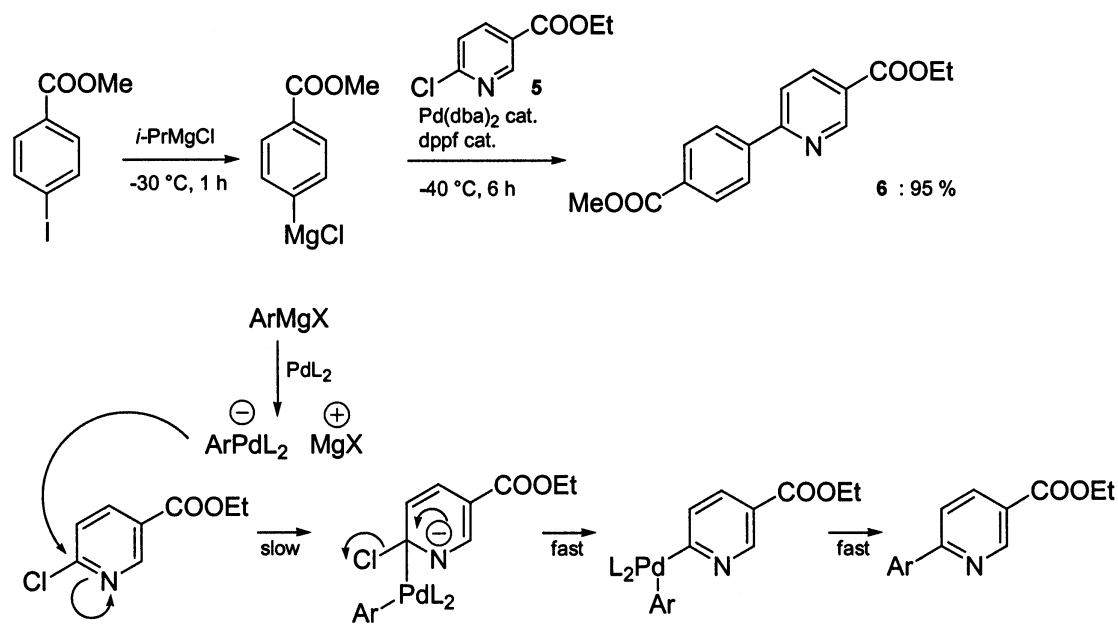

Scheme 3

Copper(I)-mediated cross-coupling reactions of functionalized arylmagnesium compounds with functionalized primary alkyl iodides and benzylic bromides proceed smoothly at room temperature in the presence of $\mathrm{P}(\mathrm{OMe})_{3}$, affording the expected $\mathrm{Csp}^{3}-\mathrm{Csp}^{2}$ cross-coupling products like $\mathbf{7}$ and $\mathbf{8}$ (Scheme 4).

This exchange reaction can successfully be applied to the preparation of various new functionalized alkenyl- and cyclopropyl magnesium species. Thus, Z-ethyl 3-iodocrotonate $\mathbf{9}$ is readily converted into the corresponding alkenylmagnesium species 10, which, after the reaction with various elec- 


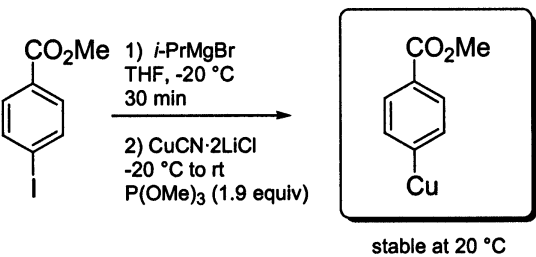

stable at $20^{\circ} \mathrm{C}$

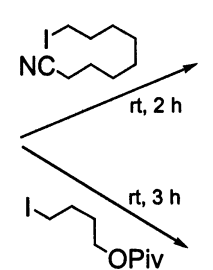

$8: 89 \%$

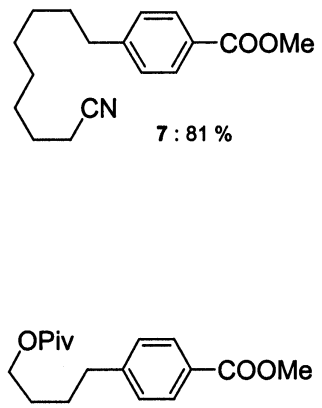

\section{Scheme 4}

trophiles like ethyl (2-bromomethyl)acrylate, 3-iodo-2-methyl-2-cyclopentanone, or benzaldehyde, affords the products 11-13 (Scheme 5).

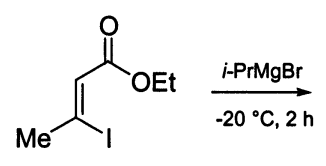

9<smiles>C=C(CC(C)=CC(=O)OCC)C(=O)OCC</smiles>

$11: 69 \%$

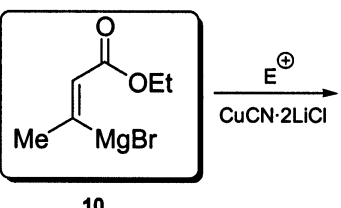<smiles>CCOC(=O)/C=C(/C)C1CCC(=O)C1C</smiles>

12 : $69 \%$<smiles>CCOC(=O)/C=C(/C)F</smiles>

11<smiles>CC1=CC(=O)OC(c2ccccc2)[I-]1</smiles>

13 : $75 \%$

\section{Scheme 5}

Interestingly, the 2-iodo unsaturated lactone $\mathbf{1 4}$ is similarly converted into the corresponding magnesium species 15 by the reaction with $i$-PrMgCl. After the addition of various electrophiles in the presence of $\mathrm{CuCN} \cdot 2 \mathrm{LiCl}$, the expected products of type 16 are obtained in 52-81\% yield (Scheme 6).

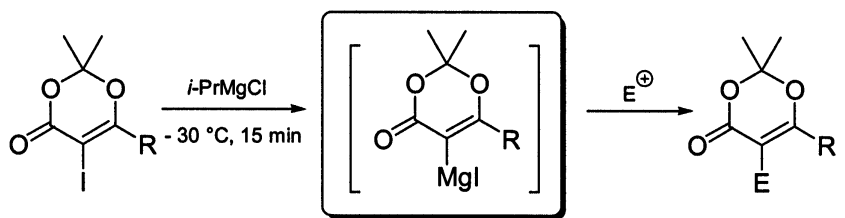

$14: R=M e, P h$<smiles>[R]C1=C(C(O)c2ccccc2)C(=O)OC(C)(C)O1</smiles><smiles>C=C(COCC)CC1=C(C)OC(C)(C)OC1=O</smiles>

$65 \%$
$15: R=M e, P h$<smiles>CC1(C)OC(=O)C(Sc2ccccc2)=C(c2ccccc2)O1</smiles>

$68 \%$<smiles>CC1(C)OC(=O)C([Si](C)(C)C)=C(c2ccccc2)O1</smiles>

$52 \%$

Scheme 6

$\mathrm{R}=\mathrm{Me} ; 76 \%$
$\mathrm{R}=\mathrm{Ph} ; 81 \%$

(C) 2002 IUPAC, Pure and Applied Chemistry 74, 11-17 


\section{FUNCTIONALIZED CHIRAL SECONDARY ALKYZINC REAGENTS FOR MICHAEL ADDITIONS WITH UMPOLUNG}

Chiral secondary alkylzinc compounds can be readily prepared via a stereoselective hydroboration, boron-zinc exchange sequence. The reaction can be applied to cyclic and acyclic trisubstituted alkenes such as 17, allowing the relative stereocontrol of four chiral centers (Scheme 7) [4,5].

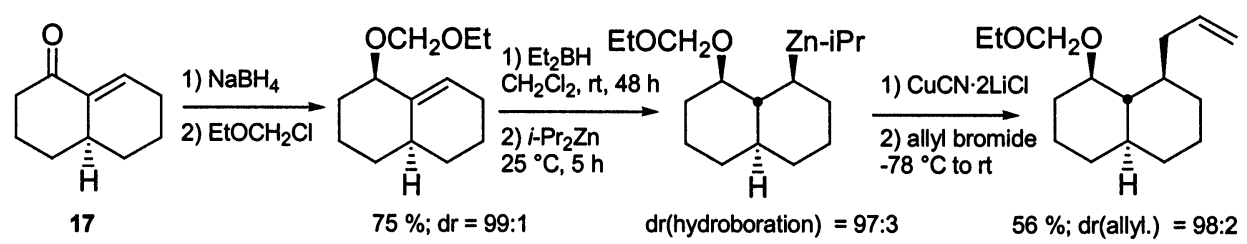

\section{Scheme 7}

The reaction of these chiral zinc reagents proceeds with a broad range of electrophiles with retention of configuration. This stereoselectivity is also observed in open-chain systems like E- and Z-18 (Scheme 8) [6].

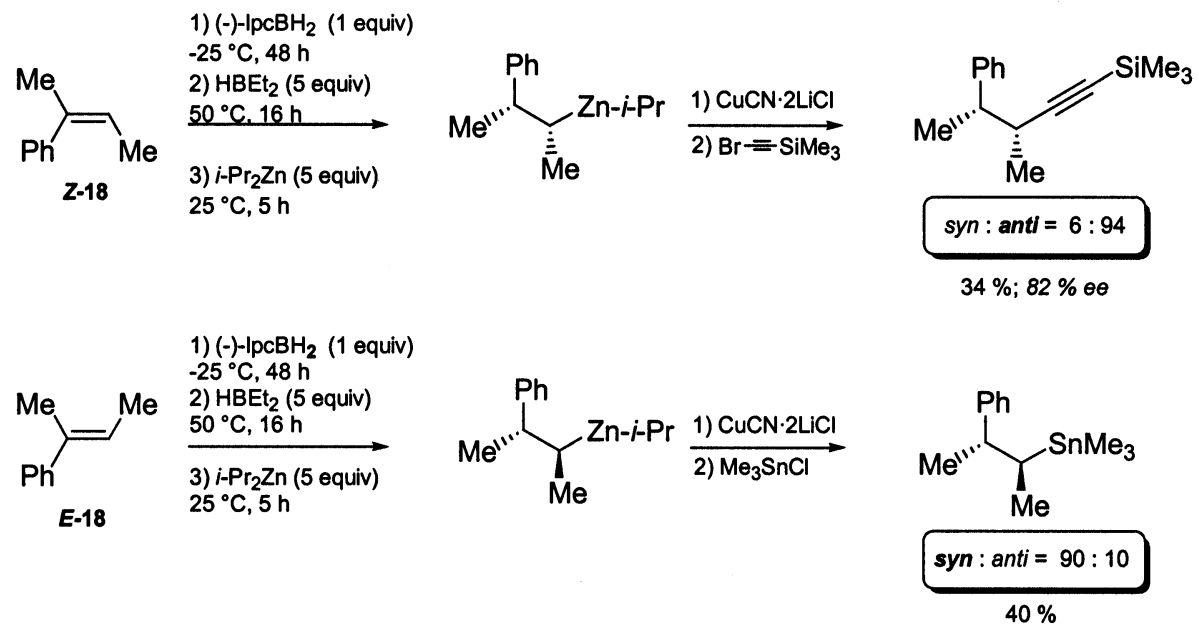

Scheme 8

This methodology has been applied in a Michael addition with inversion of polarity. Thus, the protection of an unsaturated aldehyde or ketone as an acetal or a ketal produces, after asymmetric hydroboration with (-)-IpcBH $\mathrm{BH}_{2}$ and boron-zinc exchange, the chiral organozinc reagent 19, which reacts with several carbon electrophiles, furnishing the expected products with high retention of configuration. This sequence can also be applied to protected exo-alkylidene cyclohexanone leading to the chiral organozinc reagent $\mathbf{2 0}$, which reacts with high retention of the configuration producing the allylated compound 21 in 51\% yield (Scheme 9). 


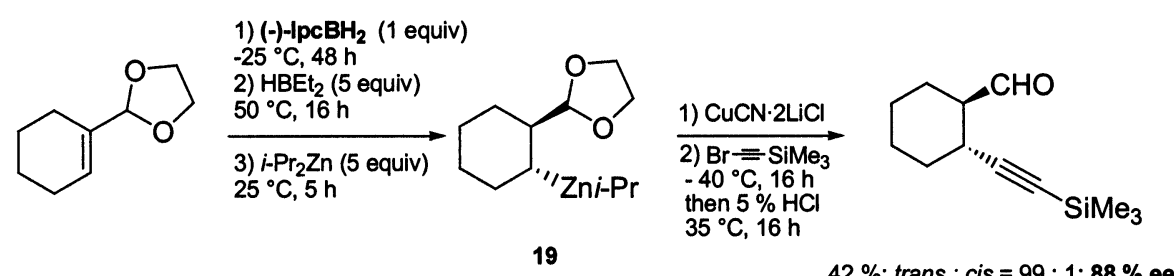

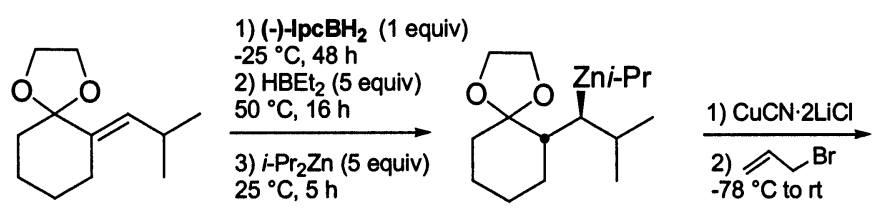

20

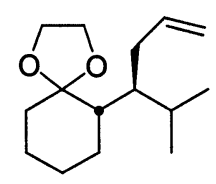

21

$51 \%$; trans : cis $=96: 4$

Scheme 9

\section{NEW CHIRAL 1,2-DIPHOSPHINES FOR THE ASYMMETRIC Rh-CATALYZED HYDROBORATION}

Cyclic chiral allylic alcohols such as $\mathbf{2 2}$ are readily converted into the corresponding phosphinite $\mathbf{2 3}$. By heating to $110^{\circ} \mathrm{C}$, a 2,3-sigmatropic shift occurs leading to a chiral phophineoxide (24), attached to a quaternary carbon atom with complete retention of configuration. This reaction can be applied to chiral diols such as $\mathbf{2 5}$, leading to a variety of 1,2-diphosphines of type $\mathbf{2 6}$. These diphosphines give excellent results in the rhodium-catalyzed hydroboration of styrenes $[7,8]$. This reaction has also been extended to the preparation of chiral 1,2-diamines (Schemes 10 and 11) [9].<smiles>CC1=C(I)C(=O)CCC1</smiles><smiles>CC1=C(I)[C@@H](O)CCC1</smiles>
22 : $97 \% ; 99 \%$ ee<smiles>CC1=C(I)[C@@H](OP)CCC1</smiles>

23<smiles>C[C@]1(P(=O)([18OH])[18OH])CCCC=C1I</smiles>

$24: 80 \% ; 99 \%$ ee

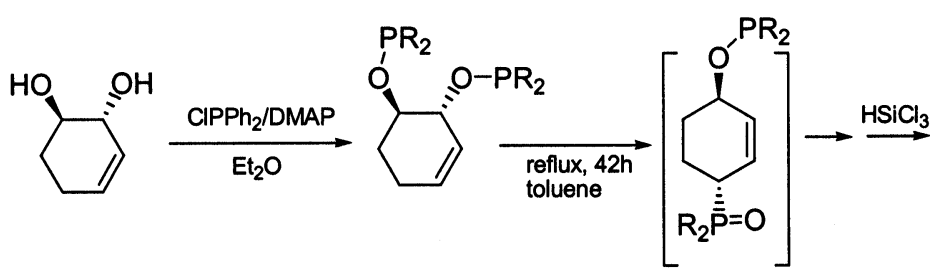

25 : $99 \% \theta \theta$
26 : $72-79 \% ; 99 \%$ ee

Scheme 10 


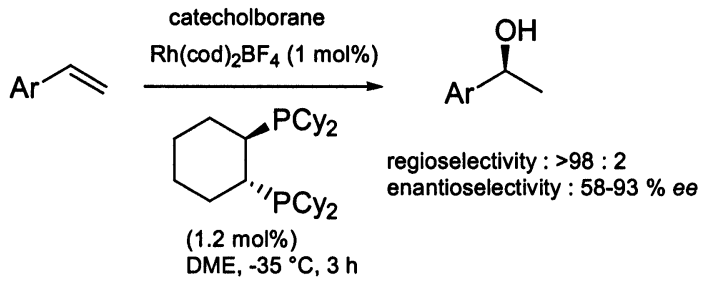<smiles>CC(O)c1ccc(F)cc1</smiles>

$81 \%$

$93 \%$ ee (3h)<smiles>CC(O)c1cccc(F)c1</smiles>

$62 \%$ $76 \%$ ee $(15 h)$<smiles>Cc1ccc(C(C)O)cc1</smiles>

$82 \%$ $92 \%$ ee (3h)<smiles>Cc1cccc(C(C)O)c1</smiles>

$83 \%$ $91 \%$ ee (4h)

Scheme 11

\section{CATALYTIC ADDITION OF CARBONYL COMPOUNDS AND PHOSPHINES TO ALKENES}

Recently, we have shown that nitriles and ketones add under mild conditions to styrenes in the presence of catalytic amounts of $t$-BuOK [10]. We have now found that $t$-BuOK also catalyzes the addition of ketones and nitriles to vinylic silanes, phosphines and thio-derivatives [11]. Furthermore, these conditions also allow a smooth addition of $\mathrm{R}_{2} \mathrm{PH}$ and $\mathrm{R}_{2} \mathrm{P}(\mathrm{O}) \mathrm{H}$ to various alkenes, allowing the preparation of various functionalized phosphines. Applications to the preparation of chiral 1,2-diphosphines will be presented (Scheme 12).

$\mathrm{Ph}_{2} \mathrm{P}$

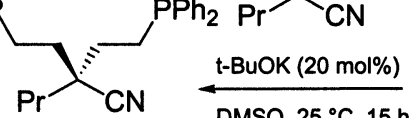
$80 \%$

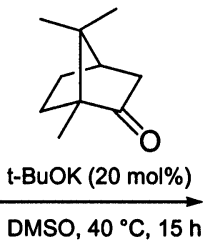

DMSO, $40^{\circ} \mathrm{C}, 15 \mathrm{~h}$

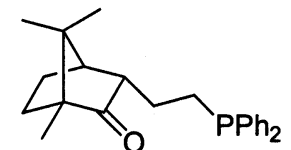

$72 \%$

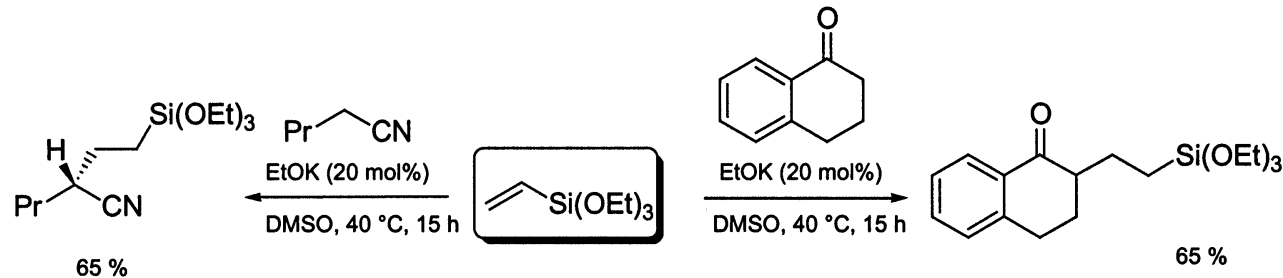

Scheme 12 


\section{REFERENCES}

1. A. Boudier, L. O. Bromm, M. Lotz, P. Knochel. Angew. Chem., Int. Ed. 39, 4415 (2000).

2. G. Varchi, A. E. Jensen, W. Dohle, G. Cahiez, P. Knochel. Synlett 477 (2000).

3. L. Bérillon, A. Leprêtre, A. Truck, N. Plé, G. Quéguiner, G. Cahiez, P. Knochel. Synlett 1359 (1998).

4. A. Boudier and P. Knochel. Tetrahedron Lett. 40, 687 (1999).

5. A. Boudier, E. Hupe, P. Knochel. Angew. Chem., Int. Ed. 39, 2294 (2000).

6. E. Hupe and P. Knochel. Org. Lett. 3, 127 (2001).

7. S. Demay, F. Volant, P. Knochel. Angew. Chem. Int. Ed. 40, 1235 (2001).

8. For pioneer work in the field of asymmetric Rh-catalyzed hydroboration: (a) J. M. Brown, D. I. Hulmer, T. P. Langzell. J. Chem. Soc., Chem. Commun. 1673 (1993); (b) A. Togni, C. Breutel, A. Schnyder, F. Spindler, H. Laudert, A. Tijani. J. Am. Chem. Soc. 116, 4062 (1994); (c) K. Burgess and M. J. Ohlmeyer. Chem. Rev. 91, 1179 (1991).

9. S. Demay, A. Kotschy, P. Knochel. Synthesis 6, 863 (2001).

10. A. L. Rodriguez, T. Bunlaksananusorn, P. Knochel. Org. Lett. 2, 3285 (2000).

11. T. Bunlaksananusorn, A. L. Rodriguez, P. Knochel. Chem. Commun. 745 (2001). 